
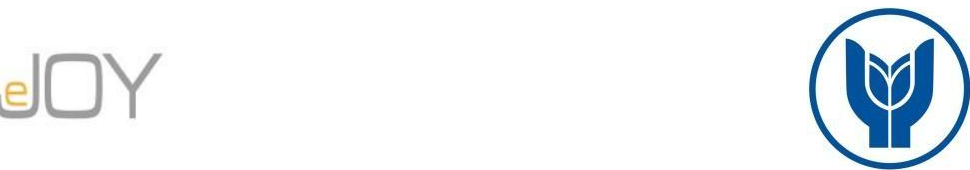

Tuna, Ö., Ural, M. N. / Journal of Yasar University, 2021, 16/62, 639-658

\title{
Üst Düzey Yöneticilerin Liderlik Tarzlarının Sosyal Medya Üzerinden Analizi
}

\section{Analysis of Leadership Styles of Senior Managers via Social Media}

\author{
Özlem TUNA, Afyonkarahisar Sağlık Bilimleri Üniversitesi, Türkiye, ozltuna@hotmail.com \\ Orcid No: 0000-0002-5842-7889 \\ Mustafa Nuri URAL, Gümüşhane Üniversitesi, Türkiye, mnu23@yahoo.com \\ Orcid No: 0000-0001-7011-401X
}

\begin{abstract}
Öz: Günümüz yeni krizleri beklenmedik ölçüde büyük ölçekli, yeni ya da benzeri görülmemiş konularda, kendini belirli bir sektörle sinırlamayan, siyasi, doğal ya da teknolojik nedenlerden kaynaklanan, ayn anda bir toplumu ya da pek çok ülkeyi etkileyen ve nedenlerinin karmaşık ve tanımlanmasının çok zor olması gibi özellikler taşımaktadır. Yaşanan bu küresel sağlık krizi yeni kriz tanımının pek çok özelliğini bünyesinde barındırmaktadır. Bu ortamda liderliğin zorluğu bu ve benzeri riskleri önlemek ya da firsata dönüş̧ürebilmektir. Üst düzey liderler kriz öncesinde, kriz sirasında ve sonrasında anahtar faktördür. Çünkü liderin kalitesi ve liderlik tarzı krizin uzunluğunu, şiddetini ve nihai sonuçlarını etkilemektedir.

Bu çalı̧̧manın temel amacı Fortune 500 Türkiye Listesinde (2020) yer alan şirket üst düzey yöneticilerinin pandemi sürecinde sergiledikleri liderlik tarzlarının belirlenmesidir. Çalışmada işletmelerin kriz ya da belirsizlik durumundan çımasına yardımcı olabilecek liderlik tarzlarından dönüşümcü, etkileşimci, demokratik ve otoriter liderlik konu edilmiştir. Nitel araştırma yönteminin kullanıldığı araştırmada veriler, şirket üst düzey yöneticilerine ait kişisel Twitter paylaşımlarından sağlanmıştır. Elde edilen veriler kodlanarak sinıflandırılmış, temalar ve alt temalar elde edilmişstir. Veriler MAXQDA yazılımı kullanılarak analiz edilmiştir. Yapılan analiz sonucunda üst düzey yöneticilerin dört liderlik tarzından otoriter liderlik dışındaki liderlik tarzlarına uygun söylemlerde bulunduğu tespit edilmiştir. Ayrıca, yöneticilerin yaptıkları paylaşımların gelecek odaklllk, örgüt, toplum veya gruba fayda sağlama, izleyicileri motive etme, değer yaratan faaliyetlere odaklanma ve ödüllendirme ile başartyı pekiştirme gibi büyük çoğunluğu dönüşümcü liderliğe ait özelliklerde yoğunlaşttğı görülmüştür.
\end{abstract}

Anahtar Kelimeler: Liderlik Tarzları, Kriz Yönetimi, Covid 19, Doküman Analizi, Twitter

\section{JEL Siniflandirmasi:M10, M12, D83, C88}

Abstract: Today's new crises have characteristics such as being unexpectedly large-scale, being on new or unprecedented issues, being not limited to a particular sector, arising from political, natural or technological reasons, affecting a society or many countries at the same time, and the reasons are complex and being very difficult to define. This global health crisis experienced contains many features of the new crisis definition. The challenge of leadership in this environment is to prevent these and similar risks or to turn them into opportunities. Senior leaders are a key factor before, during and after the crisis. Because the leader's quality and leadership style affect the length, severity and final results of the crisis.

The main objective of this study is to determine the leadership styles of the company's top executives in the Pandemic Process, which are on the Fortune 500 Turkey List (2020). The study discussed transformative, interactive, democratic and authoritarian leadership from leadership styles that can help businesses get out of crisis or uncertainty. In the research using qualitative research method, data was obtained from personal Twitter posts of company senior executives. The resulting data were encoded and classified, and themes and subthemes were obtained. The data was analyzed using MAXQDA software. As a result of the analysis, it was determined that senior executives made statements in accordance with leadership styles other than authoritarian leadership from four leadership styles. In addition, it has been observed that the posts of the managers concentrate on the characteristics of transformational leadership, such as future-oriented, benefiting the organization, society or group, motivating the audience, focusing on activities that create value and reinforcing success by rewarding.

Keywords: Leadership Style, Crisis Management, Covid 19, Document Analysis, Twitter

Jel Classification: M10, M12, D83, C88

Makale Geçmiși / Article History

Başvuru Tarihi / Date of Application

Kabul Tarihi / Acceptance Date
: 30 Ocak / January 2021

: 28 Şubat / February 2021 


\section{Giriş}

Tüm dünyada ekonomiler, özel ve kamu kurumları ile toplumun tüm kesimleri 2020'nin ortalarından itibaren Covid-19 un yarattığı gerçeklikle karşı karşıya kalmaya başladı. Covid19 sadece dünyanın değil, aynı zamanda işyeri ekosistemlerinin DNA'sını da birçok yönden değiştirdi. Bu dönemde işletmeler zorda kalan tedarik zincirlerini, ürün hatlarını, müşterileri ve çalışanları ile ilişkilerini eski haline getirmek ve canlandırmak için farklı liderlik tarzlarına ihtiyaç duydular. Salgının beklenmedik ve öngörülemeyen durumlarının yanında bilgi akışındaki zayıf bağlantı ve aksaklıklar nedeniyle pek çok ülkede siyasi liderleri, kamu ve özel kurum yöneticilerini kriz önlemleri almaya zorladı.

Kriz, kurumların normal işleyişini aksatan ve hemen harekete geçilmesini gerektiren, öngörülemeyen bir durumdur. Krizler önceden tahmin edilemediği ve normal süreçleri devre dışı bıraktığı için, etkin bir kriz yönetimi ve sağlam bir yönetim becerisi gerektirmektedir. Günümüzde yaşanan yeni krizler geçmiştekilerden birçok bakımdan farklılık göstermekte ve kriz tanımına yeni boyutlar eklemektedir. Bu krizler yaşamın devam etmesini sağlayan tüm sistemlerin ve alt yapıların işleyişini şiddetli bir şekilde tehdit etmekte ve çözüm yollarını yetersiz bırakmaktadır. Bu krizler coğrafi sınırları kolaylıkla aşarak birden çok şehri, bölgeyi, ülkeyi veya kıtayı tehdit ederken, belirli bir sektörle de (sağlı, enerji, inşaat vb.) sınırlı kalmayan bir yapıya sahiptir. Aynı zamanda bu krizler yönetişim yapılarının ve süreçlerinin meşruiyet temelini zayıflatma eğilimindedirler (Boin, 2009). Politik, kurumsal ya da sivil toplum fark etmeksizin tüm liderler bu yeni kriz durumunda etkili bir liderlik sergileyebilmek için değişmek zorunda olduklarının farkına vardılar. Bu salgın deneyimi bizlere iş birliğine dayanan, iletişim odaklı, şeffaf, proaktif ve güven inşa edebilen liderliğin etkili olduğunu gösterdi.

Literatürde işletmelerin kriz ya da belirsizlik durumundan çıkmasına yardımcı olabilecek liderlik tarzlarına ilişkin pek çok çalışma (Desyatnikov, 2020; Hasan \& Rjoub 2017; Morin, 2016; Celik, Akdemci \& Akya, 2016; Sommer, Howell \& Hadley, 2016; Alkharabsheh, Ahmad \& Kharabsheh; 2013; Shadraconis, 2013; Zhang, Jiab \& Gu, 2012; Bass \& Riggio, 2006) bulunmaktadır. Bu dönemlerde uygulanan liderlik tarzları konusunda literatür değerlendirildiğinde, dönüşümcü (taransformasyonel), etkileşimci (transaksiyonel), demokratik ve otoriter liderliğin ön plana çıktığı görülmektedir. Bu çalışmada da adı geçen liderlik tarzları konu edilmiştir. Bazı çalışmalar özellikle dönüşümcü liderliğin krizden çıkış için uygun olabileceğine vurgu yaparken (Morin, 2016; Sommer, Howell \& Hadley, 2016; Chen \& Zhang, 2011; Bass \& Riggio, 2006; Kelly, 2005; Avolio \& Bass, 1995); baz1ları da karizmatik liderlikle kriz arasında ilişki kurmuştur (Arslan, 2009; King, 2002; Pillai, 1996; 
Bryman, 1993). Örneğin Amerikan başkanlarının karşılaştıkları krizlerin sayısının karizmalarının derecelendirmeleriyle ilişkili olduğunu ya da 11 Eylül krizinden sonra Başkan Bush'un basında karizmatik dil kullanımı açısından daha sempatik göründüğünü tespit eden çalışmalar mevcuttur (Halverson, Murphy \& Riggio, 2004). Bu çalışmada karizmatik liderliğin ele alınmaması dönüşümcü liderliğin karizmatik liderliğin de dâhil olduğu birden fazla liderlik tarzını (karizmatik liderlik, motive edici liderlik, entelektüel uyarıcı liderlik ve bireye yönelik ilgi gösteren liderlik) kapsayan bir niteliğe sahip olmasından kaynaklanmaktadır (Bass, 1995). Çoğu yazar etkileşimci ve dönüşümcü liderliğin kavram ve uygulamada farklı olduğu konusunda hemfikir olsa da birçok yazar dönüşümcü liderliğin etkileşimci liderliğe önemli ölçüde değer kattığını ve bunun da daha yüksek düzeyde bireysel, grup ve örgütsel performansa yol açtığına inanmaktadır. Ayrıca etkileşimci liderliğin dönüşümcü liderliği kapsadığını savunan yazarlar da mevcuttur (Odumeru \& Ogbonna, 2013). Dönüşümcü liderlik etkileşimci liderliğin daha vizyoner ve gelecek odaklı genişletilmiş versiyonu olarak da değerlendirilmektedir (Aydın, 2020). Bazı kaynaklarda mevcut liderliğin kriz zamanı işlevsiz kalabileceğinden hatta kriz zamanı acil tepki verilebilmesi için otoriter bir liderlik tarzının tercih edilebileceğinden bahsedilmektedir (Bird, 2001; King, 2007). Yine bazı kaynaklarda da kriz sonrası işletmelerin tekrar toparlanması sürecinde demokratik bir tarzın etkili olabileceğinden bahsedilmektedir. İş birliği ve takım çalışması kriz sonrası durumlarda en etkili uygulamalar olarak değerlendirilmektedir (Asuncion, Giurintano, Hansen, Hopper \& Vobora, 2006).

Covid-19 salgınının neden olduğu sosyo-kültürel ve ekonomik kriz, liderlerin bugün karşı karşıya olduğu zorluk türlerinin aşırı bir örneğidir. Yıkıcı gücü ve varoluşu tehdit eden etkileri tamamen beklenmedik olan bu krizden çıkabilmek, özel ya da kamu fark etmeksizin tüm yöneticilerin sergiledikleri liderlik tarzlarına bağlı olacaktır. Covid-19 salgınının etkin olduğu 2020 y1lı liderlerin kriz dönemlerindeki yeteneklerini sergilemeleri için bulunmaz bir firsattır. $\mathrm{Bu}$ doğrultuda çalışmayla Fortune 500 Türkiye Listesinde (2020) yer alan ilk 15 şirket yöneticisinin 1 Ocak-31 Aralık 2020 tarihleri arasındaki 12 aylık süreçte kişisel Twitter hesaplarından yaptıkları paylaşımlar liderlik tarzlarının belirlenebilmesi amacıyla analiz edilmiştir.

\section{Kriz Dönemlerinde Liderlik}

Liderlik ile ilgili çalışmalar Sanayi Devriminden sonra artış gösterse de kavram ilk çağlardan beri herkesin ilgisini çekmektedir. Özellikle son 50 yıl liderlik alanında yoğun bir şekilde uluslararası araştırmalara tanık oldu. Bu ilgi şaşırtıcı değildir liderlik konuları örgütsel başarı 
için hayati bir öneme sahiptir. Stratejik ve etkili bir liderlik örgüt üyelerinin kârlılığının sağlanması, üretkenliği ve rekabet avantajının sürdürülmesi zordur (Yahaya \& Ebrahim, (2016). Bu denli önemli bir konu olan liderliğe ilişkin tarih boyunca birçok tanım yapılmıştır. Çok boyutlu bir kavram olan liderlik hakkında, genel kabul görmüş tek bir tanım bulunmamaktadır. Her bir liderlik tanımı, kavramın değişik boyut ve yönlerini ifade etmekte, farklı açılara ışık tutmaktadır. En eski tanımlardan biri liderliği insanların ekonomik, siyasal vb. güç ve değerleri kullanmak suretiyle bağımsız ya da ortak şekilde belirledikleri amaçları gerçekleştirmek üzere takipçilerini harekete geçmeye teşvik etme süreci şeklinde tanımlamıştır (Burns, 1978). Yammarino (150: 2013) ise binlerce liderlik tanımını özetlemeye çalışmış ve liderliği "lider (örn. amir, süpervizör) ve takipçilerinin amaç (vizyon, misyon) ve işleri (örn. hedefler, hedefler, görevler) isteyerek (zorlamadan) birlikte başarmasıdır” şeklinde tanımlamıştır.

Liderlik küresel olarak tüm örgütler için giderek daha zor, karmaşık ve çok yönlü bir hal almaktadır. $\mathrm{Bu}$ nedenle 'en iyi' liderlik tarzının ne olduğuna ilişkin yeni sorular sorulmaktadır. Dahası liderlikle ilgili kayda değer bir literatürün varlığına rağmen halen en yanlış anlaşılan iş kavramlarından biri olmaya devam etmektedir. Bir liderin seçtiği liderlik tarzı iç ya da dış tüm paydaşları derinden etkiler. Bu nedenle farklı ortamlarda farklı liderlik tarzlarının kullanılması ve lider ile takipçileri arasındaki ilişki çok önemlidir (Gandolfi \& Stone, 2018). Çoğu lider genellikle kendilerini rahat hissettikleri bir veya iki liderlik tarzına bağlı kalmaktadır. Buradaki zorluk birden fazla liderlik tarzına sahip olan liderlerin, durumları teşhis ederek doğru zamanlarda doğru liderlik tarzlarını kullanabilmeleridir. Literatürde liderlik ile ilgili çalışmalarda, içinde bulunulan ortamsal koşullar, liderliğin yaşandığı süreç ve liderin kişisel özellikleri dikkate alınarak farklı liderlik tarzlarının ortaya konulduğu görülmektedir (Bakan \& Büyükbeşe, 2010). Günümüz liderleri (politik, kurumsal ya da sivil toplum liderleri), dinamik bir küresel baskı ve sürekli değişen risklere karşı hareket etmek zorundadırlar. Dünya Ekonomik Forumu ${ }^{1}$ (WEF) 2019 küresel riskler raporunda bu riskleri doğal felaketler (kuraklık, orman yangını, pandemi vb.), iklim değişikliği etkilerinin azaltılması ve önlem almadaki başarısızlık, siber saldırılar, insan yapımı çevre felaketleri, biyoçeşitlilik kaybı ve ekosistem çöküşü, aşırı hava olayları şeklinde sıralamıştır. Liderliğin zorluğu bu ve benzeri riskleri önlemek ya da firsata dönüştürebilmektir. Üst düzey liderler kriz öncesinde, kriz sırasında ve sonrasında anahtar faktördür. Çünkü liderin kalitesi ve liderlik tarzı krizin uzunluğunu, şiddetini ve nihai sonuçlarını etkilemektedir (Klann, 2003).

\footnotetext{
${ }^{1}$ https://www.weforum.org/reports/the-global-risks-report-2019 (Erişim tarihi: 17.01.2020)
} 
Aşağıda işletmelerin kriz ve belirsizlik dönemlerinde etkili olduğu düşünülen liderlik tarzlarından dönüşümcü, etkileşimci, demokratik ve otoriter liderlikten kısaca bahsedilmiştir.

Dönüşümcü Liderlik: Kriz ortamları acil karar almayı ve uygulamayı gerektirir ve bu nedenle vizyon sahibi liderler gerektirir. Günümüz dünyasında liderlik, geleceğe yönelik öngörü, örgütün geleceği için gerçekçi bir vizyon ve hedeflerin belirlenmesini ve insanların bu hedeflerin gerçekleştirilmesi yönünde motive edilmesini içerir. Vizyonu olan ileri görüşlü liderler, çalışanın potansiyelini iyi değerlendirebilir ve onları yaptıklarından daha iyisini yapabileceklerine ikna edebilirler. Böylece vizyonu olan liderler, kriz göstergelerini algıladıkları anda harekete geçer, personele ve ekibe ona göre rehberlik ederler (Fener \& Çevik, 2015). Bass (1985) tarafından ortaya atılan dönüşümcü liderlik, kriz yönetimi ve örgütsel değişim için benzersiz bir tarz olarak kabul edilmektedir. Kriz dönemlerinde bu liderler, çalışanların eğilim ve ihtiyaçlarını belirler ve onları işe kanalize edebilmek için idealleştirilmiş etki, entelektüel teşvik, ilham verici motivasyon ve bireysel destek gibi benzersiz kişilik özellikleri sergilerler. Dönüşümcü liderler, personelin motivasyonu ve performansı üzerinde derin bir etkiye sahip olmak için kurum vizyonunu günlük faaliyetlerle başarılı bir şekilde bütünleştirebilirler. Ayrıca bu liderler, ortak vizyona doğru çalışanları iş birliğine teşvik ederler, bireylere değer verir ve gerekli desteği sağlarlar, personeli yeniliği benimsemeye ve rutinleri kırmaya teşvik ederler (Chen \& Zhang, 2011). Covid-19 salgını sırasında, yenilikçi işletmelerin kaynaklarını ön saftaki sağlık çalışanları için yüz maskeleri, vantilatörler ve koruyucu giysiler üretecek şekilde değiştirmeleri; yemek hizmetleri sektöründeki şirketlerin, yemek hazırlamak ve hastanelere teslim etmek için müşterilerinden binlerce sponsorluk toplaması ya da teknoloji şirketlerinin, öğretmenlere sanal öğrenme ve gelişmiş internet yetenekleri konusunda yardımcı olmak için ücretsiz web kameraları ve eğitim araçları sunmasını birer dönüşümcü liderlik örneği olarak görmek mümkündür (Ray, 2020).

Etkileşimci Liderlik: Bu tarz liderlik örgütün önemine, süreçlere ve hedeflere yönelik günlük işlere odaklandığı için dönüşümcü liderliği tamamlayıcı niteliktedir. Etkileşimci liderler, ekiplerin faaliyetlerini operasyonel ve taktik düzeylerde organize etmenin önemini anlayan süreç yöneticileridir yani bu yöneticiler günlük olarak her şeyin sorunsuz bir şekilde ilerlemesini sağlamakla ilgilenirler (Sirmenis \& O’Brien, 2019). Örgütün bürokratik yapısı içinde meşru otoriteye dayanan etkileşimci liderlikte, hedeflerin açıklığa kavuşturulması, görev ve sonuçlar (Korkat, 2019), sürekli program geliştirme, özel amaçlar belirleme ve problemlerin çözülmesinde olağanüstü gayret gösterme (Yeşil, 2016) gibi konular önem taşımaktadır. Daha çok yöneticilik özellikleri taşıyan bu liderler, çalışanlarla ilişkisini bir 
“değiş- tokuş" süreci olarak görür ve mevcut yönetim tekniklerini verimli ve kurallara uygun biçimde uygulamaya koymaya çalışırlar (Bakan, 2009). Çalışanlara karşı hedeflere ulaşıldığında ödüllendirme ya da takdirle bir tür koşullu ödül liderliği sergilemiş olurlar. Bu ödüller ücret, terfi, ikramiyeler ve iş başarısı için takdir etme şeklinde olabilir (Khan, Nawaz \& Khan, 2016).

Kriz sırasında krizden önce kullanılan bilgiler, planlar ve yapılar artık kullanılmayabilir. $\mathrm{Bu}$ önemli durumsal değişiklikler meydana geldiğinde etkileşimci liderler koşulların değiştiğini fark edemeyebilir veya kabul edemeyebilirler. Bu nedenle bu tarzı benimseyen liderler hızla değişen bir çevrenin taleplerini karşılamada yetersiz kalabilirler (Shadraconis, 2013).

Demokratik liderlik: Demokratik liderler, çalışan üretkenliğinin ve memnuniyetinin artmasına yardımcı olma, çalışanlara rehberlik etme ve çalışanlara yetki devri astların bilgi paylaşımına izin verme gibi çoğu liderlik tarzından daha yüksek çalışan memnuniyeti sağlanır (Sharma, 2013). Ayrıca olumlu bir örgüt ikliminin yaratılmasına yardımcı olan ve astların kararlara katılımlarının sağlanması ile motive edilmelerinden dolayı olumlu bir liderlik tarzı olarak kabul edilirler (Arıkan, 2001). Bu liderler çoğunlukla çalışanları etkilemek için uzmanlık ve karizmatik güçlerini kullanırlar (Daft, 1991). Sorunlar ortaya çıktığında ve acil kararların alınması gerektiğinde, durumu tartışmak için konuyla ilgili katılımcılar sürece dahil edilir ve nihai karar olarak çoğunluğun görüşü alınır. Ancak, sürece katılım üretkenliği artırsa da karar vermede zaman alıcı bir süreçtir ve bu demokratik liderliğin önündeki önemli engellerden biri olarak görülmektedir (Hackman \& Johnson, 1996).

Otoriter Liderlik: Otoriter liderlik, kişisel egemenliği, güçlü merkezi otoriteyi, astlar üzerinde kontrolü ve sorgusuz sualsiz itaati vurgulayan bir liderlik tarzıdır. Araştırmalar, otoriter liderliğin ekip etkileşimi, çalışanların örgütsel bağlılığı, görev performansı ve çalışanların birbirlerine yardım etme davranışı gibi durumları olumsuz yönde etkilediğini ortaya koymuştur (Du, Li \&Luo, 2020). Zorlayıcı veya diktatör liderlik olarak da bilinen otoriter liderler, tüm karar verme yetkisini kendilerinde toplarlar ve politikalar, prosedürler, görevler, yapılar, ödüller ve cezalarla ilgili kararları kendileri verirler ${ }^{2}$. Bu liderlik tarzı, büyük bir baskının söz konusu olduğu ya da liderin farklı bir seçeneğinin olmadığı durumlarda kullanılabilir. Örneğin acil bir durum ya da kriz gibi özellikle stresli durumlarda, grup üyeleri otokratik bir tarzı tercih edebilir. Lider, daha az bilgili ekip üyeleriyle değerli

\footnotetext{
${ }^{2}$ https://www.oxford-review.com/oxford-review-encyclopaedia-terms/authoritarian-leadership/
} 
zamanı harcamak yerine, grubun çıkarına en uygun kararları hızla alabilir. $\mathrm{Bu}$ tarzın demokratik veya dönüşümcü liderlik yaklaşımlarıyla dengelenmesi genellikle daha iyi grup performansına yol açabilmektedir (Cherry \& Susman, 2020).

\section{Sosyal Medya}

Türkiye'de internet kullanımı başladığında saatlik PPP (Point to Point Protocol-Noktadan Noktaya Protokolü) bağlantısı için içinde şifre olan bir zarf alınması gerekmekteydi. Bu dönemde internet, siyah ekran üzerindeki BBS (Bulletin Board System- Bilgisayarlı Bilgi Sistemi)'ler ve bazı bilgi servisleri haricinde sörf anlamında pek bir içerik barındırmıyordu. İnternette bulunan içerik işletmelerin basit ve etkileşimsiz şekilde hazırladıkları kendi tanıtımlarından öteye gitmeyen internet sitelerinden ibaretti. Yıllar içerisinde bireylerin oluşturdukları içerikler, onların global web sitelerinde söz sahibi olabilmeleri ve bu kullanıcıların paylaşımlarını sunmak üzere tasarlanmış içerik yönetim sistemleri, sosyal medya ve internetin yüzünü değiştirdi. Temel karakteristik özelliklerinin açıklanması sosyal medyanın daha kolay anlaşılmasına yardımcı olacaktır. $\mathrm{Bu}$ nedenle sosyal medyanın özelliklerini aşağıdaki başlıklarda toplamak mümkündür (Mayfield, 2008);

Katılım: Sosyal medyada var olan herkesin bu alana katkı sağlayarak 'kaynak - hedef iletişim süreci’ ni şeffaf hale getirmesi.

Açıklık: Sosyal medya geri bildirime açık olması, bireyi eyleme (oylama, yorum yapma, değerlendirme, beğenme vb.) geçirme firsatı sunması ve içeriğe ulaşma adına herhangi bir sinırlama koymamaya özen göstermesi.

Diyalog: Geleneksel medya araçlarının yayın süreci monolog bir süreç izlerken sosyal medyanın, karşılıklı bir diyalog ağıyla hareket etmesi.

Topluluk: Sosyal medyanın etkili ve hızlı bir biçimde topluluklar oluşturmaya izin vermesi ve söz konusu topluluğun ortak değerlerinin bulunması ve bu minvalde hareket etmesi. Örneğin; karikatür sayfasına üye olan veya beğenenlerin bu gruba uygun içerikler paylaşması.

Bağlılık: Web sayfaları ile sosyal medya araçlarının veya platformlarının eşgüdümlü olması. Örneğin, bir kuruma ait web sayfasında verilen sosyal medya uzantılarıyla, kurumsal sosyal medya hesaplarına geçiş yapılabilmesi.

$\mathrm{Bu}$ çalışmaya veri sağlamak için kullanılan San Francisco orijinli Twitter, birçok sosyal medya platformunda olduğu gibi 10 kişilik küçük bir ekip ile başlamıştır. Önceleri kullanıcıların tweet denilen 140 karakterle sınırlı mesajlar ile içerik paylaşmasına izin veren Twitter şu an video ve resim gibi içeriklerinde paylaşılabilmesine izin vermektedir. Mesaj 
sınırı 2017'den sonra 280 karaktere çıkan Twitter, üyelik sistemi ve oturum açma esasına dayalı olarak çalışmaktadır. Twitter'ın en büyük özelliği isterseniz @ işareti kullanarak bir kişiyi isterseniz \# işareti kullanarak bir başlığı etiketleyebilmenizdir. Böylece hem etiketlenen kişi hem de o kişiyi takip edenlerin bundan haberi olmaktadır. Ayrıca kullanıcılar etiketlenen başlıklara göre de arama yapabilmekte ve bu iki araç mesajların yayılma sürecini etkilemektedir.

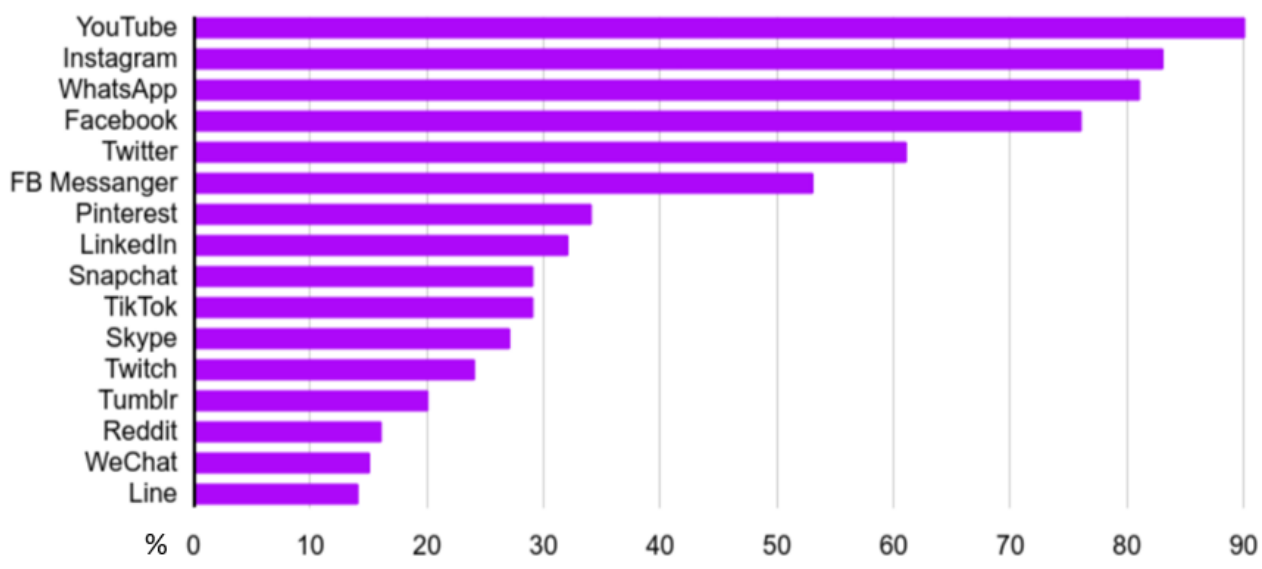

Grafik 1. Türkiye'de En Çok Kullanılan Sosyal Medya Platformları

Kaynak: BBC, 2020

Sosyal medyayı eşsiz kılan özelliği ise amacının, bireylerin yabancılarla tanışması değil, var olan bağlantılarını izleyebilme ve onlarla düşüncelerini rahatça paylaşabilme olanağıdır (Ellison, Steinfield \& Lampe, 2007). Grafik 1'de 2020 yılı için 16-64 yaş arası bireylerin sosyal medya kullanımlarının dağılımı yer almaktadır. Yine aynı grafikte Twitter'ın sosyal medya araçları arasında en çok kullanılan beşinci site olduğu görülmektedir. Özellikle bugünlerde whatsapp üzerinde yaşanan güvenlik tartışmaları olumlu sonuçlanmazsa daha da yükselmesi kaçınılmaz gözükmektedir.

Twitter Tüm dünyada da geniş kullanım alanına sahiptir. Amerika'daki 60 milyon ve Japonya'daki 45 milyonu aşan kullanıcının ardından Türkiye 10 milyondan fazla kullanıcı ile önemli bir paya sahiptir (BBC, 2020). Grafik 2'de 2020 yılı için Türkiye'nin Twitter kullanımında dünyada altıncı sırada olduğu görülmektedir. 


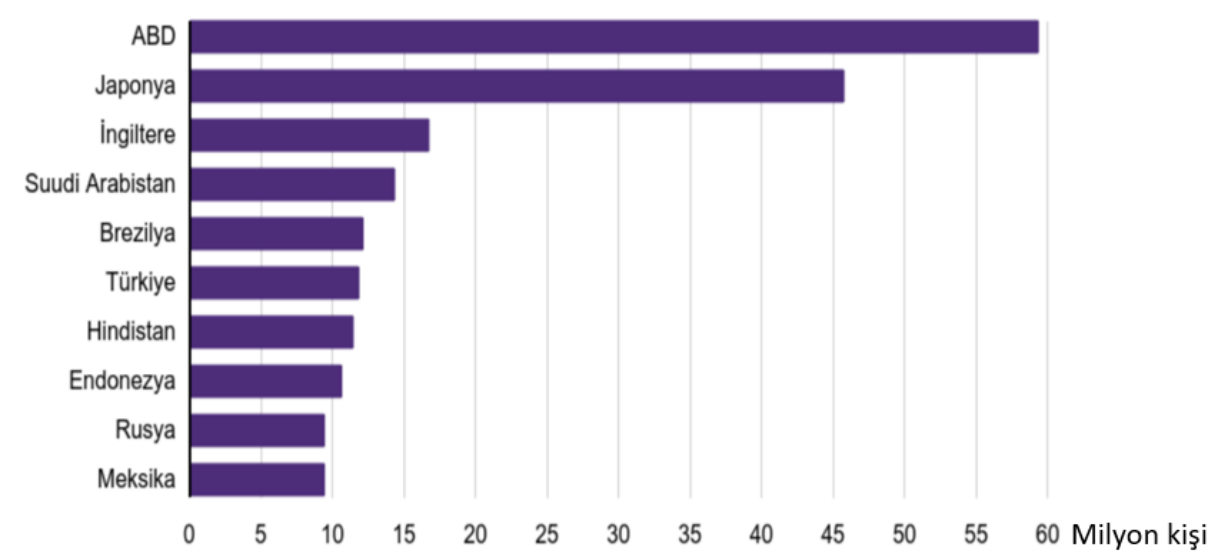

Grafik 2. Twitter'ın En Çok Kullanıldığı 10 Ülke

Kaynak: BBC, 2020

\section{Metodoloji}

\subsection{Araştırmanın Amacı}

$\mathrm{Bu}$ çalışma Fortune 500 Türkiye Listesinde (2020) yer alan şirket yöneticilerinin pandemi sürecinde sergiledikleri liderlik tarzlarının belirlenmesini amaçlamaktadır. $\mathrm{Bu}$ doğrultuda Fortune 500 Türkiye Listesinde yer alan ilk 15 şirketten kişisel Twitter hesaplarıyla paylaşım yapmış 6 yöneticinin 1 Ocak-31 Aralık 2020 tarihleri arasındaki Twitter paylaşımları incelenmiştir. Elde edilen veriler MAXQDA programı yardımıyla araştırmacılar tarafından kodlanarak sınıflandırılmış, temalar ve alt temalar elde edilmiştir. Sonrasında elde edilen veriler MAXQDA yazılımı kullanılarak analiz edilmiştir.

$\mathrm{Bu}$ çalışmanın cevap aradığı temel soruyu aşağıdaki şekilde ifade etmek mümkündür.

Bir kriz ortamı oluşturan Covid -19 salgınının yoğun olarak yaşandığ 2020 yllında Fortune 500 Türkiye'nin ilk 15'inde yer alan şirket tepe yöneticilerinin attıkları twitlere göre liderlik tarzları nelerdir?

$\mathrm{Bu}$ tip özel durumlar sosyal bilimler alanındaki araştırmacılar için bir laboratuvar niteliği taşımaktadır. Tekrarı mümkün olmayan bu dönemlerde yapılan araştırmalar özellikle kıymetlidir. Bu çalışmayla pandemi döneminde Türkiye'de faaliyet gösteren öncü işletme yöneticilerinin liderlik tarzları belirlenmeye çalışılmıştır. Çalışmanın kriz yönetimi ve liderlik alanlarında çalışan araştırmacılar için katkı sağlaması umulmaktadır.

\subsection{Yöntem}

$\mathrm{Bu}$ çalışmada nitel araştırma yöntemi kullanılmıştır. Nitel araştırma, incelediği probleme ilişkin sorgulayıcı, yorumlayıcı ve problemin doğal ortamındaki biçimini anlama uğraşı içinde olan bir yöntemdir (Guba \& Lincoln, 1994; Klenke, 2016). İnsana ilişkin algı ve olayların, sosyal gerçeklikte ve doğal ortamında derinlemesine incelenmesinin esas olduğu nitel 
araştırma, farklı disiplinleri birleştiren bütüncül bir bakış açısına da sahiptir (Hatch, 2002; Merriam \& Grenier, 2019).

Doküman analizi, yazılı belgelerin içeriğini titizlikle ve sistematik olarak analiz etmek için kullanılan bir nitel araştırma yöntemidir (Wach, 2013). Nitel araştırmada kullanılan diğer yöntemler gibi doküman analizi de anlam çıkarmak, ilgili konu hakkında bir anlayış oluşturmak, ampirik bilgi geliştirmek için verilerin incelenmesini ve yorumlanmasını gerektirmektedir (Corbin \& Strauss, 2008). Doküman incelemesi, araştırılması hedeflenen olgu ya da olgular hakkında bilgi içeren yazılı materyallerin analizini kapsamaktadır. Doküman incelemesi, bir araştırma problemi hakkında belirli zaman dilimi içerisinde üretilen dokümanlar ya da ilgili konuda birden fazla kaynak tarafından ve değişik aralıklarla üretilmiş dokümanların geniş bir zaman dilimine dayalı analizini olanaklı kılmaktadır (Yıldırım \& Şimşek, 2000).

Bu çalışma için Türkiye'deki ilk 500 şirket (Forbes 500) sıralamasına giren şirketlerin tepe yöneticileri seçilmiştir. Taramalar bir sosyal medya platformu olan Twitter üzerinden gerçekleştirilmiştir. Yapılan inceleme sonucu şirketlerin tamamının kurumsal Twitter hesapları olmasına rağmen, pek çok yöneticinin kişisel Twitter hesabının olmadığı görülmüştür. $\mathrm{Bu}$ incelemede elde edilen bulgulara göre en büyük 15 şirket yöneticisinin altısının düzenli olarak kişisel Twitter hesaplarından bildirimde bulunduğu; ikisinin Twitter hesabı olmasına rağmen bildirimde bulunmadığı; yedisinin ise kişisel Twitter hesabının bulunmadığı tespit edilmiştir (Tablo 1). Bu çalışma 2020 yılı içerisinde düzenli olarak mesaj atan 6 şirket tepe yöneticisinin paylaşımları üzerinde gerçekleştirilmiştir. Araştırmaya konu olan şirket yöneticilerine verilen kodlar ve bu şirketlerin faaliyet gösterdiği sektörler Tablo 1 'de görülmektedir.

Tablo 1. İnceleme için Seçilen Şirket Yöneticilerinin Sektörleri ve Kodları

\begin{tabular}{llll}
\hline Sira No & Sektör & Kodu & $\begin{array}{l}\text { Twitter hesabi } \\
\text { durumu }\end{array}$ \\
\hline 1 & Enerji & LD1 & Inaktif \\
2 & Enerji & LD2 & Yok \\
3 & Ulaşım & LD3 & Aktif \\
4 & Enerji & LD4 & Inaktif \\
5 & Enerji & LD5 & Yok \\
6 & Perakende & LD6 & Yok \\
7 & Otomotiv & LD7 & Aktif \\
8 & Kuyumculuk & LD8 & Yok
\end{tabular}




\begin{tabular}{llll}
9 & Beyaz eşya & LD9 & Aktif \\
10 & İnşaat & LD10 & Yok \\
11 & Madencilik & LD11 & Yok \\
12 & Maden & LD12 & Yok \\
13 & Enerji & LD13 & Aktif \\
14 & İletişim & LD14 & Aktif \\
15 & İletişim & LD15 & Aktif \\
\hline
\end{tabular}

Çalışmanın teorik kısmında da bahsi geçtiği üzere, literatürde işletmelerin kriz ya da belirsizlik durumundan çıkmasına yardımcı olabilecek liderlik tarzlarına ilişkin pek çok çalışma bulunmaktadır. $\mathrm{Bu}$ dönemlerde uygulanan liderlik tarzları konusunda literatür değerlendirildiğinde, dönüşümcü, etkileşimci, demokratik ve otoriter liderliğin ön plana çıktığı görülmektedir. Çalışmaya dört liderlik tarzı konu edilmesine rağmen, analiz aşamasında yöneticilerin otoriter liderlik özellikleri sergilemedikleri görülmüştür. Bu nedenle dönüşümcü, etkileşimci ve demokratik liderlik tarzlarına ilişkin kodlamalar yapılmıştır. Yöneticilerin Twitter paylaşımları ilgili literatüre dayandırılarak kodlanmıştır. Bu doğrultuda, dönüşümcü liderliği tanımlayan 12 özellik alt kod olarak seçilirken; etkileşimci liderlik 7 alt kodla; demokratik liderlik ise literatür taraması sonucu üç adet ayırt edici kodla temsil edilmiştir. Bu kodlar için MAXQDA'da tanımlanan renk kodları ve her bir kodun frekansı Tablo 2'de verilmiştir.

Tablo 2. Liderlik Tarzlarına ait Alt Kodlar

\begin{tabular}{cll}
\hline Renk Kodu & Kod Sistemi & Frekans \\
\hline & Kod Sistemi & 586 \\
\hline$\bullet$ & Dönüşümcü Liderlik & 467 \\
\hline$\bullet$ & Değer yaratan faaliyetlere odaklanma & 45 \\
\hline$\bullet$ & Örgüt, Toplum veya Gruba Fayda Sağlama & 88 \\
\hline$\bullet$ & İnsanların Eski İnançlarını Yıkma & 8 \\
\hline$\bullet$ & Sorumluluk Almaktan Kaçınmama & 30 \\
\hline$\bullet$ & Sinerji Yaratma & 31 \\
\hline$\bullet$ & Vizyoner olma & 20 \\
\hline$\bullet$ & Yeni fikirlere açılık & 22 \\
\hline$\bullet$ & İzleyicileri Motive Etme & 58 \\
\hline & İzleyicileri Ortak Amaca Yönlendirme & 25 \\
\hline & İhtisas Sahibi Olduğu Alanlarda Net Tavır sergileme & 20 \\
\hline
\end{tabular}




\begin{tabular}{ccc}
\hline & Gelecek Odaklılık & 100 \\
\hline$\bullet$ & Tecrübelerden öğrenmeye açıklık ve esneklik & 20 \\
\hline$\bullet$ & Etkileşimci Liderlik & 100 \\
\hline Ödüllendirme ile Başarıyı Pekiştirme & 40 \\
\hline İş standartları ve düzenlemelerini vurgulama & 21 \\
\hline Mevcut Durumun Korunması & 1 \\
\hline Geleneklere Bağlılık & 8 \\
\hline Biçimsel Yetkiyi Kullanma & 2 \\
\hline Çalışanlar İçin Standartlar Belirleme & 2 \\
\hline Problem Çözümünde Olağanüstü Gayret gösterme & 26 \\
\hline Demokratik Liderlik & 19 \\
\hline Olumlu Örgüt İklimi Oluşturma & 12 \\
\hline Uzmanlık ve Karizmatik Gücü Kullanma & 4 \\
\hline & Krizde İnisiyatif Alma & 3 \\
\hline
\end{tabular}

$\mathrm{Bu}$ çalışmada karşılan en önemli zorluklardan biri Twitter dan ham verilerin elde edilmesi olmuştur. Twitter her ne kadar arama ara yüzü aracılığı ile belirli oranda filtreleme seçenekleri sunsa da listelenen twitlerin doğrudan kopyalanmasına izin vermemektedir. Sayfa yapısı nedeniyle aynı anda kopyalanabilecek twit sayısı sınırlıdır. Yapılan aramalar sonucu twitterdan veri elde edebilmek için geliştirilmiş pek çok yöntem bulunmaktadır ve bunların çoğu twitterin yaptı̆̆ 1 son güncellemeden sonra çalışmamaktadır. Ayrıca sayfa kaynak kodunun içerisinden verilere ulaşmak da mümkün olamamaktadır. Bunun dışında geliştirici hesabı ile belirli düzeyde erişim imkânı mümkün olmuştur.

Twitter'dan veriler Python kullanılarak json formatında çekilebilmiştir. Her ne kadar doğrudan bu formatta elde edilen veriler üzerinde çalışmak mümkün olsa da gerek değişken sayısının fazlalığı gerekse fonksiyonellik anlamında sunduğu imkânlar nedeni ile dosyaların excel formatına dönüştürülmesi uygun görülmüştür.

Twitter her bir twit için tam metin twit içeriğinin yanında kullanıcı ve mesaj ile ilgili birçok ek bilgiyi de tutmaktadır. Bu alanların hepsi veri içermemekle birlikte alan sayısı beş yüzün üzerindedir. Bu nedenle öncelikle araştırma için ihtiyaç duyulan bilgileri içeren alanlar bir belgeye kopyalanarak her bir katılımcının söylemlerini ve bu söylemlerin tarihlerini gösteren ham veri formları oluşturulmuştur.

Bir sonraki aşamada bu ham veri formları MAXQDA nitel analiz programına aktarılmıştır. MAXQDA programının bir aylık deneme sürümü mevcuttur ve çalışmalar bu 
deneme sürümü üzerinden gerçekleştirilmiştir. Verilerin elde edilme süreci devam ederken bir yandan da diğer araştırmacı tarafından liderlik ile ilgili literatür taraması yapılmıştır. Literatür taramasından sonra liderlik tarzlarının özellikleri ayrıntılandırılmıştır. Sonuç olarak dönüşümcü liderlik koduna ait 12 alt kod; etkileşimci liderliğe ilişkin 7 alt kod ve demokratik liderlik ile ilgili olarak da 3 alt kod kullanılmıştır.

MAXQDA programına girilen bu kodlar her bir katılımcının metni üzerinde işaretlenmiştir. Daha sonra bu işaretlemelere bağlı olarak yine MAXQDA programında analizler ve görselleştirmeler yapılmıştır.

\section{Bulgular}

Çalışmada üç liderlik tarzına ait toplam 22 alt kod kullanılmıştır. LD9 bu 22 kodun 20 tanesine ait kodlama yaparken, LD14 22 kodun 17 sini, LD3 22 kodun 16sin1 LD15 ve LD7 22 kodun 13'ünü, LD13 ise 22 kodun 10'una denk gelen ifadeler kullanmıştır.

Tablo 3. Alt Kodların Renk, Frekans, Yüzde ve Katılımcı Sayıları

\begin{tabular}{|c|c|c|c|c|}
\hline Renk & Kod & $\begin{array}{l}\text { Kodlu } \\
\text { bölüm sayıs1 }\end{array}$ & $\begin{array}{l}\text { Kodlu Bölüm } \\
\text { Yüzdesi }\end{array}$ & Kişiler \\
\hline$\bullet$ & Değer yaratan faaliyetlere odaklanma & 45 & 7,68 & 6 \\
\hline$\bullet$ & Örgüt, Toplum veya Gruba Fayda Sağlama & 88 & 15,02 & 6 \\
\hline$\bullet$ & İnsanların Eski İnançlarını Yıkma & 8 & 1,37 & 2 \\
\hline$\bullet$ & Sorumluluk Almaktan Kaçınmama & 30 & 5,12 & 5 \\
\hline$\bullet$ & Sinerji Yaratma & 31 & 5,29 & 6 \\
\hline$\bullet$ & Vizyoner olma & 20 & 3,41 & 5 \\
\hline$\bullet$ & Yeni fikirlere açıklık & 22 & 3,75 & 5 \\
\hline$\bullet$ & İzleyicileri Motive Etme & 58 & 9,9 & 5 \\
\hline$\bullet$ & İzleyicileri Ortak Amaca Yönlendirme & 25 & 4,27 & 6 \\
\hline$\bullet$ & $\begin{array}{l}\text { İhtisas Sahibi Olduğu Alanlarda Net Tavır } \\
\text { sergileme }\end{array}$ & 20 & 3,41 & 5 \\
\hline$\bullet$ & Gelecek Odaklılık & 100 & 17,06 & 6 \\
\hline$\bullet$ & Tecrübelerden öğrenmeye açıklık ve esneklik & 20 & 3,41 & 6 \\
\hline$\bullet$ & Ödüllendirme ile Başarıyı Pekiştirme & 40 & 6,83 & 6 \\
\hline$\bullet$ & İş standartları ve düzenlemelerini vurgulama & 21 & 3,58 & 2 \\
\hline$\bullet$ & Mevcut Durumun Korunması & 21 & 3,58 & 2 \\
\hline$\bullet$ & Geleneklere Bağlılık & 1 & 0,17 & 1 \\
\hline$\bullet$ & Biçimsel Yetkiyi Kullanma & 8 & 1,37 & 4 \\
\hline$\bullet$ & Çalışanlar İçin Standartlar Belirleme & 2 & 0,34 & 2 \\
\hline$\bullet$ & $\begin{array}{l}\text { Problem Çözümünde Olağanüstü Gayret } \\
\text { gösterme }\end{array}$ & 2 & 0,34 & 1 \\
\hline$\bullet$ & Ödüllendirme ile Başarıyı Pekiştirme & 26 & 4,44 & 5 \\
\hline$\bullet$ & Olumlu Örgüt İklimi Oluşturma & 12 & 2,05 & 2 \\
\hline$\bullet$ & Uzmanlık ve Karizmatik Gücü Kullanma & 4 & 0,68 & 1 \\
\hline$\bullet$ & Krizde İnisiyatif Alma & 3 & 0,51 & 2 \\
\hline
\end{tabular}


22 kod mevcut olmasına rağmen bazı kodların daha baskın olduğu görülmektedir. Her bir alt kodun kaç lider tarafından dile getirildiği incelendiğinde ödüllendirme ile başarıyı pekiştirme, değer yaratan faaliyetler, örgüt toplum veya gruba fayda sağlamak, sinerji yaratmak, izleyicileri ortak amaca yönlendirmek, gelecek odaklılık, tecrübelerden öğrenmeye açıklık ve esneklik kodlamalarının tüm liderlerde mevcut olduğu görülmektedir. Her bir kodun kaç yöneticiye atfedildiği ve kodların toplam içerisindeki oranları Tablo'3 de görülmektedir.

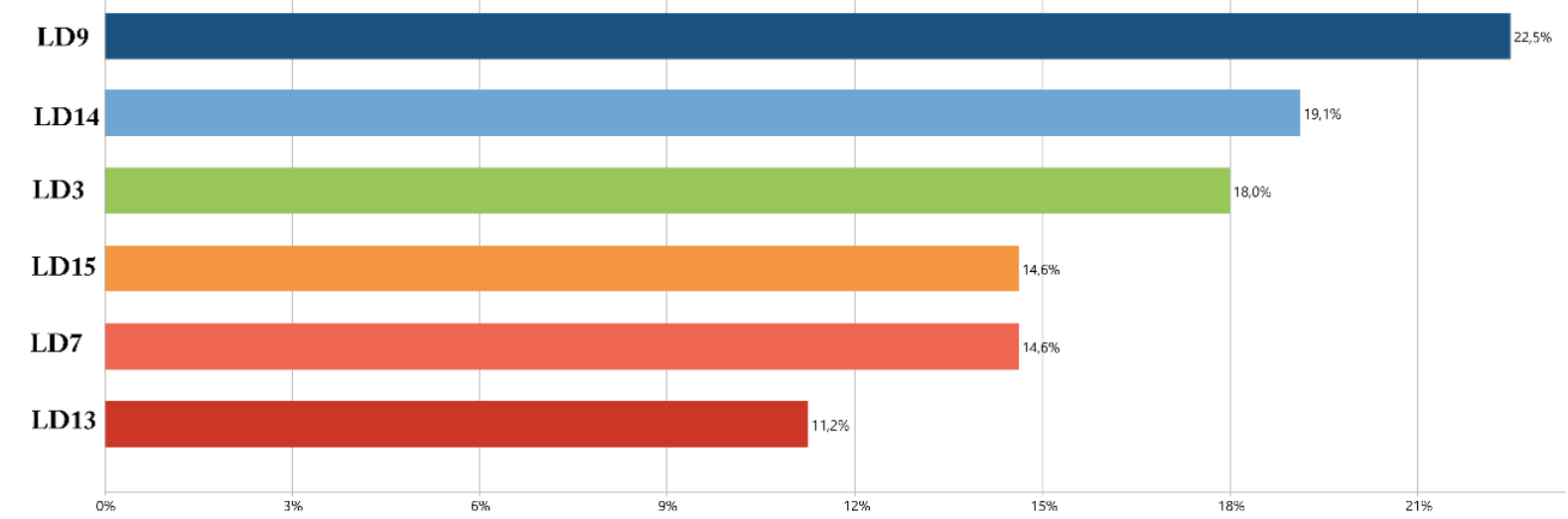

Grafik 3. Kodların Katılımcılara Göre Dağılımları

Grafikte görüldüğü gibi tüm kodlamaların yaklaşık beşte biri LD 9'ya aittir. Diğer liderlerin toplam kodlama içerisindeki yeri grafikte ayrıntılandırılmıştır. En düşük kodlama ise LD13 twitlerinde yapılmıştır.

Tablo 4. Katılımc1lara ait Mesafe Matrisi

\begin{tabular}{|c|c|c|c|c|c|c|}
\hline $\begin{array}{l}\text { Katılımeı } \\
\text { Kodları }\end{array}$ & LD14 & LD15 & LD13 & LD7 & LD9 & LD3 \\
\hline LD14 & 0 & 29,9 & 43,99 & 45,02 & 82,72 & 63,88 \\
\hline LD15 & $9,9^{2}$ & 0 & 17,64 & 16,3 & 73,9 & 52 \\
\hline LD13 & $3,9^{4}$ & 17,64 & 0 & 11,23 & 99,02 & 65,01 \\
\hline LD7 & $5,02^{4}$ & 16,3 & 11,23 & 0 & 80,07 & 59,28 \\
\hline LD9 & $\begin{array}{r}{ }^{8} \\
2,72\end{array}$ & 73,9 & 99,02 & 80,07 & 0 & 89,85 \\
\hline LD3 & $3,88^{6}$ & 52 & 65,01 & 59,28 & 89,85 & 0 \\
\hline
\end{tabular}

Tablo 4'te MAXQDA yardımıyla hazırlanan tüm katılımcılara ait mesafe matrisi görülmektedir. Matristen de görüldüğü gibi kodlama örtüşmesi birbirine en uzak olan gruplar 
LD13- LD9, LD3- LD9, LD9- LD14 çiftleridir. En yakın çıkan çiftlerin ise LD15- LD13 ve LD7-LD13 olduğu gözlenmektedir.

Tablo 5. Kodların Katılımcılara göre Dağılımı

\begin{tabular}{|c|c|c|c|c|c|c|c|}
\hline & LD3 & LD9 & LD7- & LD13 & LD14 & LD15 & Toplam \\
\hline Olumlu Örgüt İklimi Oluşturma & 0 & 8 & 0 & 0 & 4 & 0 & 12 \\
\hline Uzmanlık ve Karizmatik Gücü Kullanma & 0 & 4 & 0 & 0 & 0 & 0 & 4 \\
\hline Krizde İnisiyatif Alma & 2 & 1 & 0 & 0 & 0 & 0 & 3 \\
\hline Ödüllendirme ile Başarıyı Pekiştirme & 10 & 12 & 3 & 2 & 4 & 9 & 40 \\
\hline İş standartları ve düzenlemelerini vurgulama & 19 & 0 & 0 & 0 & 2 & 0 & 21 \\
\hline Mevcut Durumun Korunmas1 & 1 & 0 & 0 & 0 & 0 & 0 & 1 \\
\hline Geleneklere Bağlılık & 1 & 1 & 0 & 1 & 5 & 0 & 8 \\
\hline Biçimsel Yetkiyi Kullanma & 0 & 1 & 0 & 0 & 1 & 0 & 2 \\
\hline Çalışanlar İçin Standartlar Belirleme & 0 & 2 & 0 & 0 & 0 & 0 & 2 \\
\hline Problem Çözümünde Olağanüstü Gayret gösterme & 6 & 8 & 4 & 0 & 3 & 5 & 26 \\
\hline Değer yaratan faaliyetlere odaklanma & 2 & 8 & 2 & 6 & 13 & 14 & 45 \\
\hline Örgüt, Toplum veya Gruba Fayda Sağlama & 15 & 11 & 6 & 1 & 40 & 15 & 88 \\
\hline İnsanların Eski İnançlarını Yıkma & 0 & 4 & 4 & 0 & 0 & 0 & 8 \\
\hline Sorumluluk Almaktan Kaçınmama & 9 & 14 & 1 & 0 & 4 & 2 & 30 \\
\hline Sinerji Yaratma & 3 & 5 & 5 & 1 & 11 & 6 & 31 \\
\hline Vizyoner olma & 0 & 7 & 3 & 2 & 2 & 6 & 20 \\
\hline Yeni fikirlere açılık & 7 & 8 & 2 & 0 & 3 & 2 & 22 \\
\hline İzleyicileri Motive Etme & 21 & 11 & 0 & 3 & 16 & 7 & 58 \\
\hline İzleyicileri Ortak Amaca Yönlendirme & 8 & 11 & 2 & 1 & 1 & 2 & 25 \\
\hline $\begin{array}{l}\text { İhtisas Sahibi Olduğu Alanlarda Net Tavır } \\
\text { sergileme }\end{array}$ & 8 & 1 & 2 & 0 & 5 & 4 & 20 \\
\hline Gelecek Odakl1lık & 18 & 41 & 6 & 5 & 17 & 13 & 100 \\
\hline Tecrübelerden öğrenmeye açıklık ve esneklik & 1 & 15 & 1 & 1 & 1 & 1 & 20 \\
\hline TOPLAM & 131 & 173 & 41 & 23 & 132 & 86 & 586 \\
\hline $\mathrm{N}=$ Belgeler & 1 & 1 & 1 & 1 & 1 & 1 & 6 \\
\hline
\end{tabular}

Tablo 5'te tüm kodların katılımcılara göre dağılımı görülmektedir. Toplam 586 kodlamanın içinde LD9 173, LD14 132 ve LD3 131 kodlama ile önemli bir ağırlığa sahiptir. Tüm yöneticilere ait kodlamalar değerlendirildiğinde, üç liderlik tarzına ait toplam 22 alt koddan gelecek odaklılık 100 ve örgüt, toplum veya gruba fayda sağlamak ise 88 olmak üzere en yüksek frekanslara sahiptir. Yöneticiler değerlendirildiğinde LD9'nun gelecek odaklı alt koduna ait frekans değerleri ile LD14'ün örgüt, toplum veya gruba fayda sağlamak alt koduna ait frekans değerleri dikkat çekicidir. Diğer katılımcılara ait alt kodlara ilişkin frekanslar tabloda ayrıntıları ile verilmiştir. 


\section{Sonuç}

$\mathrm{Bu}$ küresel sağlık krizi, işletmelerin tüm yönetim boyutları için stratejiler geliştirmesini gerekli kılmakta ve işin sürekliliğini garantiye almak, çalışanların güvenliğini sağlamak, müşteri ve diğer paydaşlara kararlı bir şekilde cevap verebilmek gibi pek çok alanda becerilerini test etmektedir. Bu inanılmaz derecede zor ve olağandışı zamanlarda işletmelerin başarısı, çevik bir şekilde uyum sağlayabilme ve doğaçlama yeteneklerine göre şekillenmektedir. Acil uyum gerektiren kamu protokolleri; çalışanların uzaktan erişimi için alt yapının kurulması ve buna bağlı olarak müşteri verilerinin güvenliğinin sağlanması; nakit akışı, finansal planlama ve bütçeleme faaliyetlerine yönelik stratejilerin geliştirilmesi; tedarik zinciri risklerinin mümkün olduğunca minimize edilmesi; toplumun ihtiyaçlarının giderilmesinde aktif rol alma ve bu faaliyetlerin yerine getirilmesine liderlik etme işletmelerin bu süreçte ilgilenmesi gereken belli başı konuları oluşturmaktadır (Tuna, 2020). Tüm bu zorluklara liderlik etme belki de bu süreçte en zor faaliyettir. Bu çalışmayla böyle olağandışı bir süreçte Türkiye'nin en önemli şirketlerinin yönetiminden sorumlu kişilerin liderlik tarzları farklı bir bakış açısıyla değerlendirilmeye çalışılmıştır.

$\mathrm{Bu}$ doğrultuda elde edilen veriler literatüre bağlı olarak değerlendirildiğinde, yöneticilerin dört liderlik tarzından (dönüşümcü, etkileşimci, demokratik ve otoriter) sadece üçüne yönelik davranış benimsediği tespit edilmiştir. Liderlerin Twitter paylaşımlarının değerlendirildiği 12 aylık süreçte otoriter tarza ilişkin (örneğin, yasal ve zorlayıcı güç kullanma, çalışanlara yönelik kişisel değerlendirmelerde bulunma, çalışanların duygusal yönlerini görmezden gelme ve tek başına karar verme gibi) herhangi bir söylemde bulunmadığı görülmüştür. Altı yöneticinin de dönüşümcü liderliğin ödüllendirme ile başarıyı pekiştirme, değer yaratan faaliyetlere odaklanma, örgüt toplum veya gruba fayda sağlama, sinerji yaratma, izleyicileri ortak amaca yönlendirme, gelecek odakl1lık, tecrübelerden öğrenmeye açıklık ve esneklik özelliklerini destekleyecek paylaşımlarda bulunduğu tespit edilmiştir. Etkileşimci liderliğin özelliklerinden, hedeflere ulaşıldığında iş başarısını takdir etme, tüm yöneticilerce kabul gören bir davranıştır. Demokratik liderlik özellikleri ise üç lider tarafından benimsenmiştir. Demokratik liderlik özelliğini benimseyen liderlerden LD9, çoğunlukla dönüşümcü liderlik tarzı sergilerken, dikkat çekici bir şekilde 14 Mart $^{3}$ ile 16 Kasım tarihleri arasında uzmanlık ve karizmatik gücünü kullanma, krizde inisiyatif alma ve olumlu örgüt iklimi oluşturma özelliklerine yönelik paylaşımlar yapmıştır. Demokratik liderliğin krizde inisiyatif alma

\footnotetext{
${ }^{3}$ Dünya Sağlık Örgütü, 11 Mart'ta Covid-19'u pandemik bir hastalık olarak ilan etmiş ve 114 ülkede 118 bin vakanın görüldüğünü ve 4 bin 291 kişinin hayatını kaybettiğini açıklamıştır (https://www.bbc.com/turkce/haberler-dunya-51614548 (Erişim tarihi: 14.01.2021).
} 
özelliği LD3'ün 30-31 Ocak tarihlerindeki paylaşımlarında görülürken, bu paylaşımlar doğrudan pandemiye yöneliktir. LD9 dişında diğer yöneticilerin olumlu örgüt iklimi oluşturmaya yönelik paylaşımları araştırma yapılan tarihler arasında değişkenlik gösterirken, özellikle pandemiye yönelik bir duruş sergilememektedir.

Dikkat çekici bir başka sonuç mesafe matrisi sonucunda elde edilmiştir. Türkiye'nin en iyi şirketler sıralamasında ilk 15 de yer alan üç şirket yöneticisinin birbirinden farklı liderlik tarzlarını benimsemesidir. $\mathrm{Bu}$ yöneticilerden ikisi sermayesinin tamamı ve çoğunluğu devlete ait kurumlarda yönetici iken diğeri tamamen özel sermayeli bir şirketin yöneticisidir. Bu yöneticilerden LD9 ve LD13 \%99,02 oranında; LD9 ve LD3 ise \%89,85 oranında kodlama örtüşmesi ile birbirine en uzak olan yöneticilerdir. LD9 çoğunlukla gelecek odaklılık, yeni fikirlere açıklık, vizyoner olma, tecrübelerden öğrenmeye açıklık ve insanların eski inançlarını yıkma yönünde paylaşımlarda bulunmuştur. Bu paylaşımlar dönüşümcü liderliğin geleceğe yönelik öngörü, örgütün geleceği için gerçekçi bir vizyon oluşturma ve hedeflerin belirlenmesi ile insanların bu hedeflerin gerçekleştirilmesi yönünde motive edilmesine karşılık gelen özelliklerdir. Diğer iki liderin paylaşımlarının ise iş standartları ve düzenlemelerini vurgulama, problem çözümünde olağan üstü gayret, ödüllendirme ile başarıyı pekiştirme ve izleyicileri motive etme gibi çoğunluğu etkileşimci liderliğin özelliklerini destekleyen twitlerdir.

Sırasıyla gelecek odaklılık, örgüt, toplum veya gruba fayda sağlama, izleyicileri motive etme, değer yaratan faaliyetlere odaklanma ve ödüllendirme ile başarıyı pekiştirme en fazla paylaşımın yapıldığı liderlik özellikleridir. LD9 tecrübelerden öğrenmeye açıklık ve esneklik özelliğine ilişkin 15 paylaşımda bulunurken diğer yöneticiler birer paylaşımda bulunmuştur. İletişim sektöründe yer alan iki şirket yöneticisinin diğer yöneticilere nazaran daha fazla değer yaratan faaliyetlere odaklanma özelliğini destekleyecek paylaşımlarda bulunduğu görülmüştür.

Sonuç olarak, kriz ve belirsizlik dönemlerinde liderler özellikle vizyon, değerler, rol model olma, toplumsal duyarlı1ık (yardımseverlik), paydaşları destekleme, duygusal ve örgütsel dayanıklılığı güçlendirme gibi konulara dikkat ederek kriz sırasında olumlu örgüt ikliminin oluşturulmasını sağlayabilmelidir. Bu da krizin olumsuz etkisini ve krizin olası süresini azaltabilmektedir (APA, 2020; Hall, 2020; Segel, 2020; Pasmore \& Mallis, 2020; Ermut, 2020). Araştırmaya konu olan yöneticilerin bu zorlu kriz döneminde kişisel Twitter hesaplarından yaptıkları paylaşımların bu yönde olduğunu söylemek yanlış olmayacaktır. 


\section{KAYNAKÇA}

Alkharabsheh, A., Ahmad, Z.A.\& Kharabsheh, A. (2013). Characteristics of crisis and decision making styles: The mediating role of leadership styles. International Conference on Innovation, Management and Technology Research, Malaysia, 22 - 23 September.

APA (2020). How leaders can maximize trust and minimize stress during the Covid-19 pandemic American. Psychological Association, www.apa.org

Arıkan, S. (2001). Otoriter ve demokratik liderlik tarzları acısından Atatürk'ün liderlik davranışlarının değerlendirilmesi. H.U. İktisadi ve İdari Bilimler Fakültesi Dergisi, 19 (1): 231-257.

Arslan, A. (2009). Kriz yönetiminde liderlik, Akademik Bakış, Uluslararası Hakemli Sosyal Bilimler E-Dergisi, (18), Ekim - Kasım - Aralık, 1-12.

Asuncion, A., Giurintano, T., Hansen, S., Hopper, K. \& Vobora, A. (2006). Leading through disasters and recovery. Leadership APTA - Class of 2006.

Avolio, B. J., \& Bass, B. M. (1995). Multifactor leadership questionnaire. Mind Garden, 1-114.

Aydın, Ö. (2020). Liderlik kuramları açısından PKK terör örgütünde liderlik ve Abdullah Öcalan, Gazi Üniversitesi Sosyal Bilimler Enstitüsü Siyaset Bilimi ve Kamu Yönetimi Anabilim Dalı, Yayınlanmamış Doktora Tezi.

Bakan İ. \& Büyükbeşe T. (2010). Liderlik türleri ve güç kaynaklarına ilişkin mevcut-gelecek durum karşılaştırması: Eğitim kurumu yöneticilerinin algılarına dayalı bir alan araştırması. KMÜ Sosyal ve Ekonomik Araştırmalar Dergisi, 12(19): 73-84.

Bakan, İ. (2009). Liderlik tarzları ile örgüt kültürü türleri arasındaki ilişkiler: Bir alan çalışması. TISSK Akademi, 4(7): $138-172$

Bass, B. M. (1985). Leadership and performance beyond expectations. New York: Free Press.

Bass, B. M. (1995). Concepts of leadership: The beginnings. J. T. Wren içinde, The Leaders Companion Insights on Leadership Through the Ages (s. 73). New York: Free Press.

Bass, B. M. \& Riggio, R. E. (2006). Transformational Leadership, Lawrence Erlbaum Associates, Publishers Mahwah, Second Edition New Jersey London.

BBC (2020). Türkiye'de sosyal medya ne kadar ve nasıl kullanıliyor? https://www.bbc.com/turkce/haberlerturkiye 53259275\#: :text=Ocak\%20ay\%C4\%B1\%20verilerine\%20g\%C3\%B6re\%2C\%20T\%C3\%BCrk iye'de\%20ise\%2054\%20milyon\%20sosyal,15'inci\%20s\%C4\%B1rada\%20yer\%20al\%C4\%B1yor. (Erişim tarihi: 12.01. 2021)

Bird Jr., D. F.B. (2001). Quality air force in an emergency: Leadership principles and concepts for emergency response forces. Air War College Maxwell Paper No. 2, Air University, http,//www.au.af.mil/au/awc/awcgate/maxwell/mp02.pdf

Boin, A. (2009). The new world of crises and crisis management: Implications for policymaking and research, Review of Policy Research, 26 (4): 367-377.

Bryman, A. (1993). Charismatic leadership in business organizations: Some neglected issues. The Leadership Quarterly, 4: 289-304.

Burns, M. G. (1978). Leadership. Harper-Row, Newyork.

Celik, A., Akdemci, T. \& Akya, T. E. (2016). A comparison between the styles of transformational leaders and authentic leaders in crisis management. International Journal of Academic Research in Business and Social Sciences, 6 (2):183-196.

Chen, G.\& Zhang, J. (2011). Analysis on transformational leadership in postcrisis era: Evidence from Jack Welch in GE, 2011 International Conference on Electronics, Communications and Control (ICECC).

Cherry, K. \& Susman, D. (2020). Autocratic leadership key characteristics, strengths, and weaknesses of autocratic leadership. https://www.verywellmind.com/what-is-autocratic-leadership-2795314 (Erişim tarihi:16.01.2021)

Corbin, J. \& Strauss, A. (2008). Basics of qualitative research: Techniques and procedures for developing grounded theory. Thousand Oaks: Sage

Daft, R. L. (1991). Management, The Dryden Press, Second Edition.

Desyatnikov, R. (2020). Management in crisis: the best leadership style to adopt in times of crisis, https://www.forbes.com/sites/forbestechcouncil/2020/07/17/management-in-crisis-the-best-leadershipstyle-to-adopt-in-times-of-crisis/?sh=22c5972c7cb4

Du, J., Li, N.N. \& Luo, Y.J. (2020). Authoritarian leadership in organizational change and employees' active reactions: Have-to and willing-to perspectives. Frontiers in Psychology, 10, Article 3076: 1-8.

Ellison, N. B., Steinfield, C., \& Lampe, C. (2007). The benefits of Facebook "friends:" Social capital and college students' use of online social network sites. Journal of Computer-Mediated Communication, 12(4): $1143-1168$.

Ermut, N. K. (2020). Zorlu zamanların etkili ilacı: Güçlü liderlik, https://hbrturkiye.com/blog/zorlu-zamanlarinetkili-ilaci-guclu-liderlik (Erişim tarihi: 12.01.2021) 
Fener, T. \& Çevik, T. (2015). Leadership in crisis management: separation of leadership and executive concepts, 4th World Conference on Business, Economics and Management, WCBEM Procedia Economics and Finance 26: $695-701$.

Gandolfi, F.\& Stone, S. (2018). Leadership, Leadership Styles, and Servant Leadership, Journal of Management Research, 18 (4), Oct.-Dec.: 261-269.

Guba, E. G. \& Lincoln, Y. S. (1994). Competing paradigms in qualitative research. Handbook of Qualitative Research, 2(105): 163-194.

Hackman, M. Z., \& Johnson, C. E. (1996). Leadership: A communication perspective (2nd ed.). Prospect Heights, IL: Waveland Press.

Hall, J. (2020). Focus on Trust: Successful leadership in times of crisis, https://www.forbes.com/sites/johnhall/2020/03/22/focus-on-trust-successful-leadership-in-times-ofcrisis/\#5eafc73567b0 (Erişim tarihi: 19.01.2021)

Halverson, S.K., Murphy, S.E. \& Riggio, R.E. (2004). Charismatic leadership in crisis situations a laboratory investigation of stress and crisis, Small Group Research, Vol. 35 No. 5, 495-514.

Hasan, A. \& Rjoub, H. (2017). The role of effective leadership styles in crisis management: a study of Erbil, Iraq. International Journal of Economics, Commerce and Management, United Kingdom, V (4): 108121.

Hatch, J. A. (2002). Doing qualitative research in education settings. Suny Press.

Kelly, M. L. (2005). Academic adivisers as transformational leaders. The mentor: an academic advising journal. Retrieved from http://dus.psu.edu/mentor/old/articles/030101mk.htm.

Khan, Z. A., Nawaz, A. \& Khan, I. (2016). Leadership theories and styles: A literature review, Journal of Resources Development and Management, 16: 1-7.

King, G. (2002). Crisis management \& team effectiveness, a closer examination, Journal of Business Ethics, 41(3), December: 235- 249.

Klann, G. (2003). Crisis Leadership, Published by Ccl Press, Center for Creative Leadership, Greensboro, North Carolina.

Klenke, K. (2016). Qualitative research in the study of leadership. Emerald Group Publishing Limited.

Korkat, B. (2019). Liderlik tarzlarının örgüt kültürü ve yenilik performansı üzerine etkisi. Tokat Gaziosmanpaşa Üniversitesi Sosyal Bilimler Enstitüsü, İşletme Anabilim Dalı, Yayımlanmamış Doktora Tezi.

Mayfield, A. (2008). What is media? https://www.icrossing.com/uk/sites/default/files_uk/insight_pdf_files/What\%20is\%20Social\%20Media iCrossing ebook.pdf, (Erişim Tarihi: 16. 01.2021)

Merriam, S. B. \& Grenier, R. S. (2019). Qualitative research in practice: Examples for discussion and analysis. San Francisco, CA: Jossey-Bass Publishers.

Morin, A. (2016). How the best leaders turn an organizational crisis into their company's finest hour, https://www.forbes.com/sites/amymorin/2016/04/06/how-the-best-leaders-turn-an-organizational-crisisinto-their-companys-finest-hour/\#3cfcfa384c3b (Erişim tarihi: 11.12.2020)

Odumeru, J.A. \& Ogbonna, I.G. (2013). Transformational vs. transactional leadership theories: Evidence in literature. International Review of Management and Business Research, 2(2): 355-361.

Pasmore, W. \& Mallis, E. (2020). Re-set your organization for the post covid future with creative leadership, Center for Creative Leadership, www.ccl.org

Pillai, R. (1996). Crisis and the emergence of charismatic leadership in groups, an experimental investigation, Journal of Applied Social Psychology, (26)6: 543 - 562.

Ray, M. (2020). Transformational leadership: Intellectual stimulation, https://www.michelleray.com/transformational-leadership-intellectual-stimulation/ (Erişim tarihi: 15.01.2021)

Segel, L. H. (2020). Positive leadership in uncertain times, McKinsey https://www.mck_nsey.com/bus_nessfunct_ons/organ_zat_on/our-_ns_ghts/pos_t_ve-leadersh_p-_n-uncerta_n-t_mes (Erişim tarihi: 12.01.2021)

Shadraconis, S. (2013). Organizational leadership in times of uncertainty: Is transformational leadership the answer? LUX: A Journal of Transdisciplinary Writing and Research from Claremont Graduate University, 2(1), Article 28: 1-15.

Sharma, J. K. \& Singh, S.K. (2013). A study on the democratic style of leadership. International Journal of Management \& Information Technology, 3 (2):54-57.

Sirmenis, D., O’Brien, W. (2019). How various leadership styles apply to corporate crisis management,https://translate.google.com.tr/?hl=tr\&tab=rT\&sl=en\&tl=tr\&text=By\%20Devin\%20Sirme nis $\% 2 \mathrm{C} \% 20 \mathrm{Witt} \% 20 \mathrm{O} \% \mathrm{E} 2 \% 80 \% 99 \mathrm{Brien} \% \mathrm{E} 2 \% 80 \% 99 \mathrm{~s} \% 3 \mathrm{~A} \& \mathrm{pp}=$ translate $\quad$ (Erişim tarihi: 04.01.2021) 
Sommer, S. A., Howell, J. M. \& Hadley, C. N. (2016). Keeping positive and building strength: The role of affect and team leadership in developing resilience during an organizational Crisis, Group \& Organization Management, 41(2): 172-202.

Tuna, Ö. (2020). Covıd-19 and new business ecosystem. Bölüm Ad1: The effects of Covid-19 on business (2020) Tuna Özlem, Gazi Kitapevi, Editör: Duygu Hıdırlığlu, Semih S. Aktuğ, Osman Yılmaz, ISBN: 978625-7727-33-4, Sayfa Sayıs1 448, İngilizce (Bilimsel Kitap)

Wach, E. (2013). Learning about qualitative document analysis. IDS Practice Paper In Brief 13.

Yahaya, R. \& Ebrahim, F. (2016). Leadership styles and organizational commitment: literature review, Journal of Management Development, 35 (2): 190-216.

Yammarino, F. (2013). Leadership: Past, present, and future, Journal of Leadership \& Organizational Studies, 20(2): 149-155.

Yeşil, A. (2016). Liderlik ve motivasyon teorilerine yönelik kavramsal bir inceleme. Uluslararası Akademik Yönetim Bilimleri Dergisi, 2 (3): 158-180.

Yıldırım, A. ve Şimşek, H. (2000). Sosyal bilimlerde nitel araştırma yöntemleri. Gözden geçirilmiş 2. Baskı. Ankara: Seçkin Yayıncılık.

Zhang, Z., Jiab, M. and Gu, L. (2012). Transformational leadership in crisis situations: evidence from the People's Republic of China. The International Journal of Human Resource Management, 23(19): 40854109. 